\title{
Dermotaxis v/s loop suture technique for closure of fasciotomy wounds: a study of 50 cases
}

\author{
Naveen Mittal ${ }^{1,2} \cdot$ Robin Bohat $^{2} \cdot$ Jagandeep Singh Virk $^{2} \cdot$ Payal Mittal $^{2}$
}

Received: 8 February 2017/ Accepted: 8 October 2017/Published online: 16 October 2017

(C) The Author(s) 2017. This article is an open access publication

\begin{abstract}
Fasciotomy incisions lead to large, unsightly, chronic wounds after surgical intervention. Classic management was to use split-thickness skin grafts, but this leads to insensate skin with reports that as many as $23 \%$ of patients are dissatisfied by the appearance of the wound. Since no skin loss has occurred with the fasciotomy incision, utilizing the dermal properties of creep, stress relaxation and load cycling, closure can be achieved in a better way. We describe using dermotaxis for skin edge approximation that is done using inexpensive equipment available readily in any standard operating room. Twenty-five patients had fasciotomy wounds closed either by dermotaxis or a loop suture technique with the inclusion criteria being closed fractures, no concomitant skin loss, fracturerelated compartment syndrome and fasciotomy performed within $36 \mathrm{~h}$. The fasciotomy incision was closed in a single stage by loop suture technique or gradually by dermotaxis once the oedema had settled between 3 and 5 days. Results were graded as excellent if approximation could be achieved, good if sutures had to be applied for protective care and poor if wounds needed to be skin-grafted. In the dermotaxis group, results were excellent in 15 , good in 8 and poor in 2 cases. In the loop suture technique group, results were excellent in 20, good in 4 and poor in 1 case. Dermal apposition using inexpensive, readily available equipment is an alternative method for closure of fasciotomy wounds. If limb oedema has settled sufficiently, closure using a loop suture can be done in a single stage. If
\end{abstract}

Naveen Mittal

Naveen.mital0501@gmail.com

\#3732 Sector 46-c, Chandigarh, India

2 Government Medical College Hospital, Sector-32, Chandigarh, India the limb remains oedematous, gradual closure can be done using dermotaxis.

Keywords Fasciotomy · Wound closure - Inexpensive · Dermotaxis · Loop suture technique

\section{Introduction}

Compartment syndrome was defined by Mubarak [1] as an elevation of the interstitial pressure in a closed osseofascial compartment that results in microvascular compromise. Early recognition and treatment via surgical decompression are paramount. However, the fasciotomy incisions can lead to large, unsightly, chronic wounds after surgical intervention [2]. The classic management of fasciotomy wounds was split-thickness skin graft $[3,4]$. In a study involving 60 patients who underwent fasciotomy wound closure with split skin grafting, Fitzgerald et al. [3] reported that $23 \%$ were upset by the appearance of the wound, $28 \%$ changed hobbies and $12 \%$ changed occupation. Since no skin loss has occurred with the fasciotomy, several authors [4-6] have considered dermatotraction to gradually or acutely close fasciotomy wounds [6]. If skin is stretched with a constant force, it will expand with time as long as it is kept under tension, a phenomenon known as mechanical creep [7]. If skin is stretched to a constant distance, it will expand and lead to a decrease in the force or tension on the skin with time, a phenomenon known as stress relaxation [7]. Recently, load cycling has been identified as another skin stretching technique based on creep. Load cycling is the incremental elongation of skin when intermittent tension is applied. Tension applied for $3 \mathrm{~min}$ is followed by a load free period of 30-60 s. The same cycle is continued until the desired elongation is achieved [8,9]. Our hypothesis 
was that closure of fasciotomy wounds by dermatotraction could be performed in a staged fashion or in a single stage, using inexpensive equipment available readily in any standard operating room.

\section{Materials and methods}

There were 50 patients in total. There were two groups of twenty-five patients each, all with fasciotomy wounds, that had closure either by dermotaxis or the loop suture technique. The inclusion criteria were fasciotomies done for compartment syndrome after closed fractures, without concomitant skin loss, done within $36 \mathrm{~h}$; the exclusion criteria were open fractures, skin loss, non-fracture-related compartment syndrome and presentation after $36 \mathrm{~h}$. The diagnosis of compartment syndrome was made on clinical examination. The type of assisted closure, debridement repeated before final closure, need for skin graft and evidence of infection were recorded. We used the standard two-incision technique for fasciotomy of the leg using the posteromedial and anterolateral incisions. The closure of posteromedial incision was carried out using Vicryl (No. 1) sutures to the subcutaneous tissue and mattress sutures for the skin with Ethilon (No. 2-0) (Fig. 1). The wound on the lateral side was closed either by dermotaxis or a loop suture technique.

In dermotaxis (Singh's skin traction) method, two parallel Kirschner wires $(1.5 \mathrm{~mm})$ are passed through the dermis on either side of the wound margins and interconnected by compression device consisting of threaded rod having two blocks and compression knob. Gradual compression was applied daily at the rate of $1 \mathrm{turn} / 12 \mathrm{~h}$ on both sides of the wound (Figs. 2, 3, 4).

The loop suture technique involves using corrugated drains and Ethilon (No. 1) suture. It is an extension of the purse string suture technique where a surgical suture is passed as a running stitch in and out along the edge of a wound in such a way that when the ends of the suture are drawn tight the wound is closed. Two corrugated drains (1, 2) are anchored to the skin adjacent to the fasciotomy incision using Ethilon (No. 1) suture. The sutures are then passed from one edge of the wound through the skin and

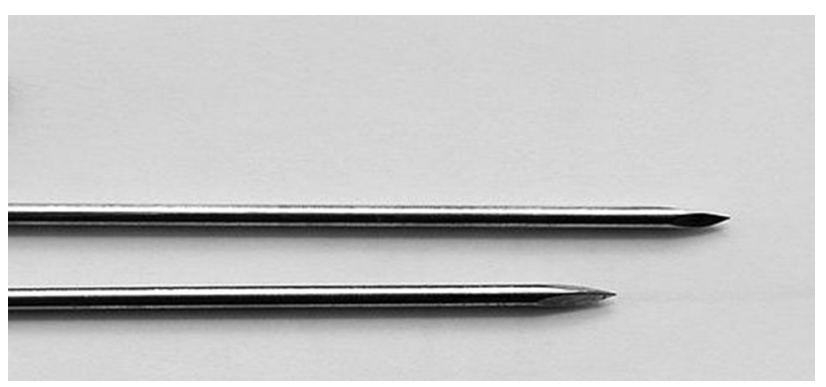

Fig. 2 Showing dermotaxis apparatus consisting of K-wires

corrugated drain to the other in an alternating fashion (Figs. 5, 6, 7). A moist dressing was applied, and the wound was left for 2 days to allow the skin to accommodate the approximation obtained.

\section{Results}

The ages ranged from 21 to 60 years. The results were graded as excellent if approximation could be achieved, good if a secondary procedure, e.g. sutures had to be applied for protective care, and poor if the wounds had to be skin-grafted. In the dermotaxis group, results were excellent in 15, good in 8 and poor in 2 cases. In the loop suture technique, group results were excellent in 20 , good in 4 and poor in 1 case (Figs. 8, 9, 10).

The results of the two techniques are compared in Table 1.

\section{Discussion}

The various techniques of fasciotomy wound closure are:

- Split-thickness skin grafting.

- Healing by secondary intention.

- Vacuum-assisted closure (VAC).

- Dermal apposition.

These techniques each have advantages or disadvantages as compared with other techniques, including time to wound closure, cost and complications.

Fig. 1 Showing closure of posteromedial incision by Vicryl no. 1 suture to the subcutaneous tissue and mattress sutures to the skin with Ethilon 2-0

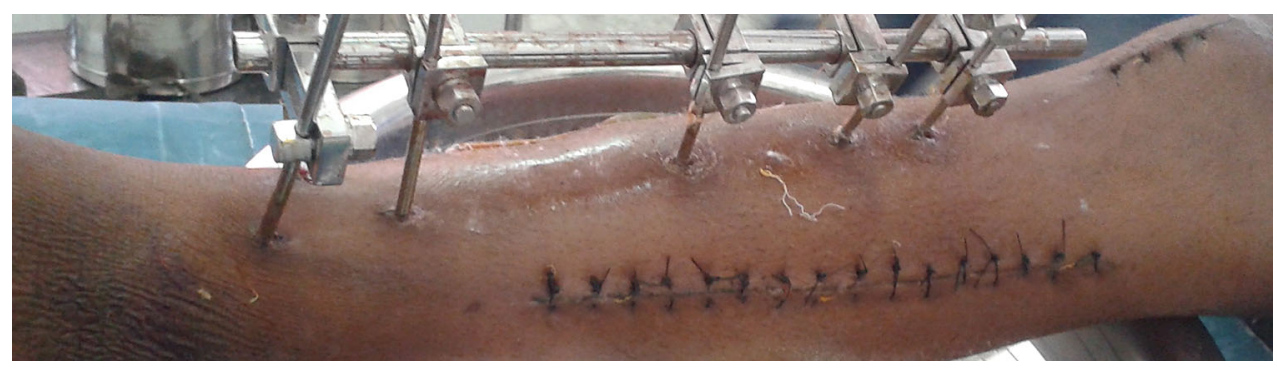




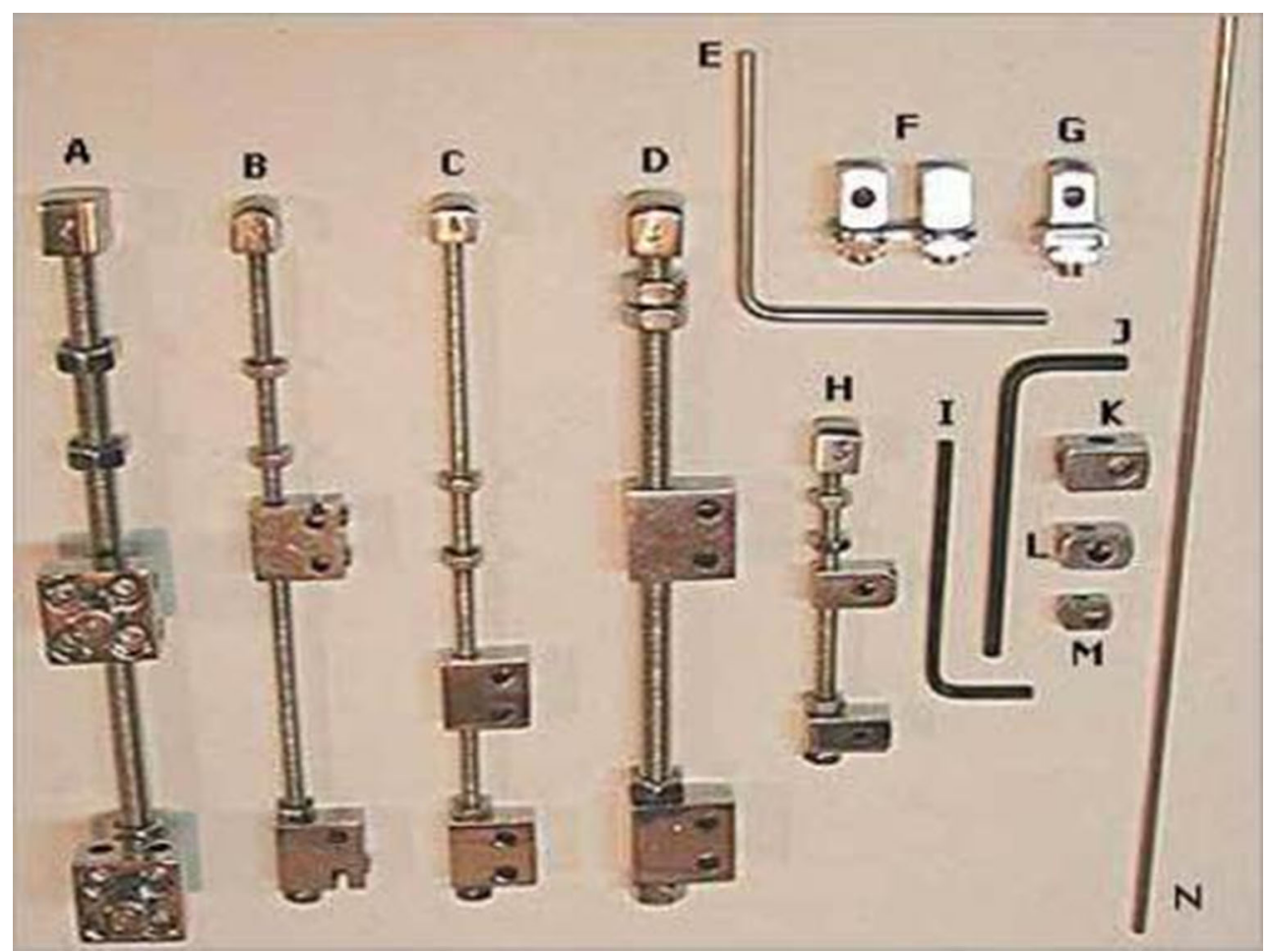

Fig. 3 Showing dermotaxis apparatus consisting of compression knob

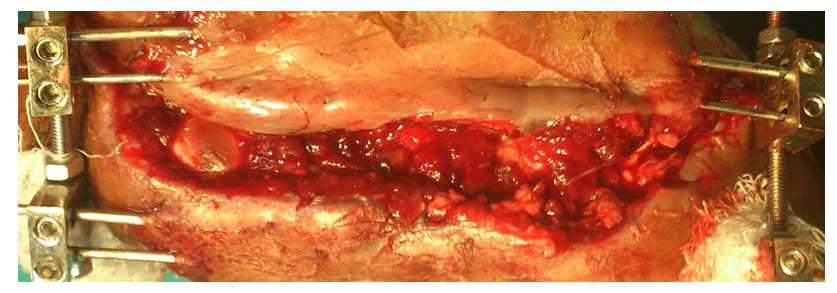

Fig. 4 Showing wound after application of dermotaxis

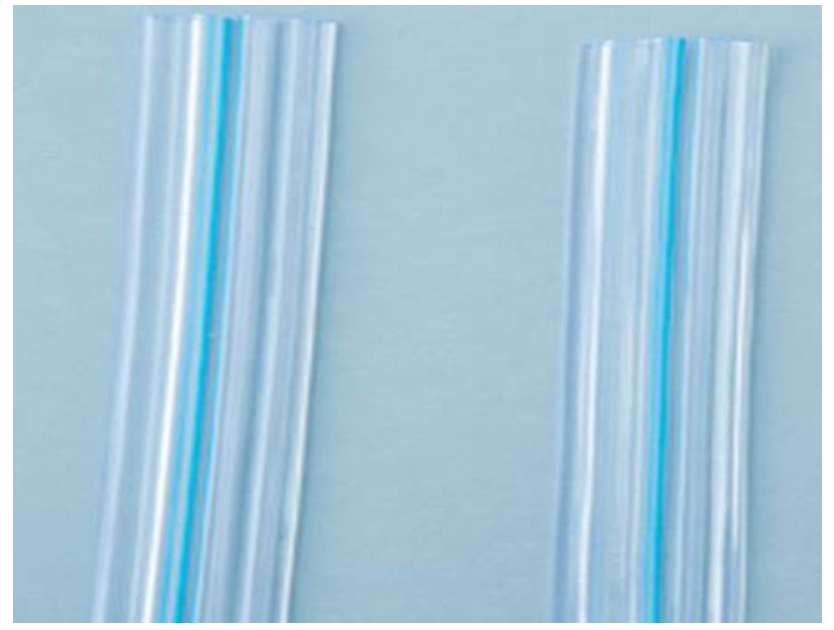

Fig. 5 Showing corrugated drains



Fig. 6 Showing loop suture technique 
Fig. 7 Showing complete approximation of the wound achieved with loop suture technique



Split skin grafting

Skin grafting is the most common procedure to close fasciotomy wounds [10]. The repair is tension free but requires another operative procedure, creating another wound [11, 12]. The overall cover is thin, producing an unappealing scar aesthetically that is without sensation $[11,12]$.

\section{Secondary intention}

Secondary intention uses skin contraction to heal the fasciotomy wound [11]. It is free from the complications associated with grafting, but complete healing requires an average time of 3-4 months with dressings to be changed 1-3 times daily [11]. The normalization of the scar contour may take 4 years which is impractical today [11].

\section{Vacuum-assisted closure (VAC)}

Vacuum-assisted closure(VAC) uses negative pressure to exploit the elastic properties of skin [10]. The negative pressure created reduces oedema, promotes blood flow, lowers bacterial count and increases the tissue granulation

Fig. 9 Showing maximum approximation achieved with dermotaxis, after which suture applied for approximation




Table 1 Comparison of results of dermotaxis and loop suture technique

\begin{tabular}{lll}
\hline Technique & Dermotaxis & Loop suture \\
\hline Number of patients & $25($ male 16 ; female 9) & 25 (male 20; female 5) \\
Average dimensions of wound & $18 \times 8 \mathrm{~cm}$ & $15 \times 6 \mathrm{~cm}$ \\
Average closure time & 12 Days & 10 Days \\
Management & Daily tightening & Wound care \\
Limitations & K-wire cutout & Excessive skin tension \\
Cost & Rs 300/- $(\$ 5)$ & Rs $100 /-(\$ 2)$ \\
Number of tightening sessions & $5-7$ & $2-3$ (If required) \\
Debridement & 2 patients & 4 Patients \\
Complications & Infection-3 patients & Infection-1 \\
\hline
\end{tabular}

rate to create a wound that is more conducive to closure [10]. However, the daily cost of VAC is approximately $\$ 174$ with the dressing changes every 2-3 days [13-15]. In addition, VAC may fail to provide adequate skin edge approximation for final closure with $5-10 \%$ of cases requiring a secondary procedure [16]. Patients who underwent NPWT-assisted closure were at higher risk for skin grafting than patients who underwent vessel loop closure. The overall time to closure was greater than loop suture technique $[13,17]$.

\section{Dermal apposition}

The technique of dermatotraction for closure of fasciotomy wounds was first described by Cohn in 1986 [18]. In the literature, innovative techniques focusing on dermal apposition can be subdivided into closure in a single stage using inexpensive equipment and closure by gradual compression. The technique of closure by gradual compression is further subdivided into the expensive and inexpensive techniques.

The comparison of the expensive techniques is highlighted in Table 2. These have the advantage of a tension control mechanism, but cost and availability are against use as a standard technique.

The comparison of the inexpensive techniques is highlighted in Table 3. The inexpensive techniques, the shoelace technique and the peadiatric urinary catheter technique, both have the disadvantage of point loading as there is stretching on the skin at a point and are labourintensive requiring the patient to be admitted to hospital. In contrast, our technique of dermotaxis creates uniform tension all across the wound and is not as labour-intensive as the gradual tightening can be performed at home by the patient as with adjustments to an Ilizarov fixator.

Table 2 Dermal apposition using expensive techniques

\begin{tabular}{|c|c|c|c|}
\hline Author & Device & Advantages & Disadvantages \\
\hline Hirshowitz et al. [5] & Sure closure device & $\begin{array}{l}\text { 1. Can measure the tension } \\
\text { across the wound edges }\end{array}$ & $\begin{array}{l}\text { 1. Not readily available } \\
\text { 2. Expensive }(\$ 300-\$ 500)\end{array}$ \\
\hline McKenney et al. [19] & $\begin{array}{l}\text { STAR (suture tension } \\
\text { adjustment reel) }\end{array}$ & & 1. Expensive \\
\hline Janzing and Broos [6] & $\begin{array}{l}\text { Marburger skin approximation } \\
\text { system }\end{array}$ & & $\begin{array}{l}\text { 1. Not readily available } \\
\text { 2. Expensive }\end{array}$ \\
\hline Barnea et al. [4] & Wisebands device & $\begin{array}{l}\text { 1. Tension feedback control } \\
\text { mechanism to safeguard } \\
\text { against excessive skin } \\
\text { tensioning }\end{array}$ & $\begin{array}{l}\text { 1. Not readily available } \\
\text { 2. Expensive }\end{array}$ \\
\hline Taylor et al. [20] & Skin anchors & $\begin{array}{l}\text { 2. Evenly distributed force over } \\
\text { the full length of the wound }\end{array}$ & $\begin{array}{l}\text { 1. Not readily available } \\
\text { 2. Expensive }\end{array}$ \\
\hline Medina et al. [12] & $\begin{array}{l}\text { Silver bullet wound closure } \\
\text { device (SBWCD) }\end{array}$ & & $\begin{array}{l}\text { 1. Daily tightening } \\
\text { 2. Scar tenderness } \\
\text { 3. Numbness of extremity } \\
\text { 4. Expensive }(\$ 575)\end{array}$ \\
\hline Geertruida et al. [16] & Ty-raps & & 1. Not readily available \\
\hline
\end{tabular}


Table 3 Dermal apposition using inexpensive techniques

\begin{tabular}{|c|c|c|c|}
\hline Author & Device & Advantages & Disadvantages \\
\hline Zorrila et al. [21] & Shoelace & $\begin{array}{l}\text { 1. Readily available } \\
\text { 2. Inexpensive }\end{array}$ & $\begin{array}{l}\text { 3. Tightening every } 48 \mathrm{~h} \\
\text { 4. Scar contracture }\end{array}$ \\
\hline $\begin{array}{l}\text { Ravinder et al. } \\
\text { [22] }\end{array}$ & Dermotaxis (Singh's skin traction) & $\begin{array}{l}\text { 1. Wounds with exposed } \\
\text { bone }\end{array}$ & 1. K-wire cutout \\
\hline \multirow[t]{2}{*}{ Eid et al. [23] } & \multirow[t]{2}{*}{$\begin{array}{l}\text { Paediatric urinary catheters }+ \text { skin } \\
\text { staples }\end{array}$} & 1. Readily available & $\begin{array}{l}\text { 1. Point loading on the staples may lead to their } \\
\text { failure }\end{array}$ \\
\hline & & 2. Inexpensive & 2. No safe mechanism against excess tension \\
\hline Kakagia et a [13] & Shoelace & $\begin{array}{l}\text { 1. Readily available } \\
\text { 2. Inexpensive }\end{array}$ & $\begin{array}{l}\text { 3. Daily tightening } \\
\text { 4. Replacement of device }\end{array}$ \\
\hline \multirow[t]{2}{*}{ Our study } & \multirow[t]{2}{*}{ Dermotaxis } & $\begin{array}{l}\text { 1. No point loading } \\
\text { 2. Postop easy }\end{array}$ & 1. Sutures to approximate wound \\
\hline & & $\begin{array}{l}\text { 3. Readily available } \\
\text { 4. Inexpensive }\end{array}$ & 2. K-wire cutout \\
\hline
\end{tabular}

\section{Single closure}

Chiverton and Redden used a subcuticular Prolene (No. 2-0) suture in 6 patients achieving good results in 4 patients. One intra-operative complication was encountered where an attempt to close the lateral wound led to breaking of the suture which had then to be replaced [24]. Marek et al. used spinal needle and towel clips for approximation in a case report. He used capillary refill for assessing skin vascularity, but this does not provide an assessment of the architecture of dermis; the study was limited to a single case [7]. Our loop suture technique uses the same concept as load cycling. The good and poor results were attributed to the thinning properties of skin at the rate of $6 \%$ per decade in addition to the dimensions of the original wound [7]. Caution is needed with these techniques as there is a potential risk of re-elevating compartment pressure; additionally, the excessive amount of traction may lead to blanching or impairment of skin vascularity.

The results of dermatotraction have been shown to be superior as it provides a better cosmetic appearance, sensate skin, avoids donor site morbidity and is easy to apply even in centres with limited resources. However, the disadvantages are that application has to await the settling of limb oedema after compartment syndrome, which may require three to five days postoperatively. When these devices are applied with oedema present, the tension created by the combination of the two can cause skin necrosis and a recurrence of the compartment syndrome. Therefore, close monitoring of the limb during closure is required.

\section{Conclusion}

Dermal apposition using inexpensive, readily available equipment is a good method for closure of fasciotomy wounds. Both the methods have significant advantages to other techniques. If the reduction of limb oedema permits closure using the loop suture technique, then closure can be done in a single stage. If this oedema is still present, then gradual closure is done using dermotaxis. Despite its disadvantages, split skin grafting cannot be excluded totally given the ease of the procedure and its established role for wound closure.

\section{Compliance with ethical standards}

Conflict of interest The authors declare that they have no conflict of interest.

Ethical approval All procedures performed in studies involving human participants were in accordance with the ethical standards of the institutional and/or national research committee and with the 1964 Helsinki declaration and its later amendments or comparable ethical standards.

Open Access This article is distributed under the terms of the Creative Commons Attribution 4.0 International License (http://crea tivecommons.org/licenses/by/4.0/), which permits unrestricted use, distribution, and reproduction in any medium, provided you give appropriate credit to the original author(s) and the source, provide a link to the Creative Commons license, and indicate if changes were made.

\section{References}

1. Mubarak SJ, Owen CA (1975) Compartmental syndrome and its relation to the crush syndrome, a spectrum of disease: a review of 
11 cases of prolonged limb compression. Clin Orthop Relat Res 113:81

2. McQueen MM, Christie J, Court-Brown CM (1996) Acute compartment syndrome in tibial diaphyseal fractures. J Bone Joint Surg [Br] 78-B:95-98

3. Fitzgerald M, Gaston P, Wilson Y, Quaba A, McQueen MM (2000) Long-term sequelae of fasciotomy wounds. Br J Plast Surg 53(8):690-693

4. Barnea Y, Gur E, Amir A et al (2006) Delayed primary closure of fasciotomy wounds with Wisebands, a skin- and soft tissuestretch device. Injury 37(6):561-566

5. Hirshowitz B, Lindenbaum E, Har-Shai Y (1993) A skinstretching device for the harnessing of the viscoelastic properties of skin. Plast Reconstr Surg 92(2):260-270

6. Janzing HMJ, Broos PLO (2001) Dermatotraction: an effective technique for the closure of fasciotomy wounds: a preliminary report of fifteen patients. J Orthop Trauma 15(6):438-441

7. Marek DJ, Copeland GE, Zlowodzki M, Cole PA (2005) The application of dermatotraction for primary skin closure. Am J Surg 190(1):123-126

8. Gibson T (1977) The physical properties of skin. In: Converse JM (ed) Reconstructive plastic surgery, vol 1. Saunders, Philiadelphia, pp 70-77

9. Branchet MC, Boisnic S, Frances C et al (1990) Skin thickness changes in normal aging skin. Gerontology 36:28-35

10. Zannis J, Angobaldo J, Marks M et al (2009) Comparison of fasciotomy wound closures using traditional dressing changes and the vacuum-assisted closure device. Ann Plast Surg 62(4):407-409

11. Boxer L, Buchman S (2002) An alternative method for closure of fasciotomy wounds: healing by secondary intention. Internet $\mathbf{J}$ Plast Surg 1(2):1-6

12. Medina C, Spears J, Mitra A (2008) The use of an innovative device for wound closure after upper extremity fasciotomy. Hand 3(2):146-151
13. Kakgaia D, Karadimas E, Drosos G, Ververidis A, Trypsiannis G, Verettas D (2014) Wound closure of leg fasciotomy: comparison of vacuum-assisted closure versus shoelace technique. A randomized study. Injury 45(5):890-893

14. Yang CC, Chang DS, Webb LX (2006) Vacuum-assisted closure for fasciotomy wounds following compartment syndrome of the leg. J Surg Orthop Adv 15:19-23

15. Saziye K, Mustafa C, Ilker U, Afksendyios K (2011) Comparison of vacuum-assisted closure device and conservative treatment for fasciotomy wound healing in ischaemia-reperfusion syndrome: preliminary results. Int Wound J 8:229-236

16. Geertruida AM, Govaert G, van Helden S (2010) Ty-Raps in trauma: a novel closing technique of extremity fasciotomy wounds. J Trauma 69:972-975

17. Fowler JR, Kleiner MT, Das R, Gaughan JP, Rehman S (2012) Assisted closure of fasciotomy wounds. A descriptive series and caution in patients with vascular injury. Bone Joint Res $1(3): 31-35$

18. Harris I (1993) Gradual closure of fasciotomy wounds using a vessel loop shoelace. Injury 24(8):565-566

19. McKenney M, Nir I, Fee T, Martin L, Lentz K (1996) A simple device for closure of fasciotomy wounds. Am J Surg 172:275-277

20. Taylor RC, Reitsma BJ, Sarazin S, Bell MG (2003) Early results using a dynamic method for delayed primary closure of fasciotomy wounds. J Am Coll Surg 197(5):872-878

21. Zorilla P, Marin A, Gomez LA, Salid JA (2005) Shoelace technique for gradual closure of fasciotomy wounds. J Trauma 59(6):1515-1517

22. Ravinder S, Gill HS, Walia JPS, Brar BS, Nagra TS (2008) Management of skin loss by dermotaxis. J Bone Joint Surg Br 90-B(SUPP 1): 25

23. Eid A, Elsoufy M (2012) Shoelace wound closure for the management of fracture related fasciotomy wounds. ISRN Orthop

24. Chiverton N, Redden JF (2000) A new technique for delayed primary closure of fasciotomy wounds. Injury 31(1):21-24 